\title{
Predicting patient attitudes to asthma medication
}

\author{
L M Osman, I T Russell, J A R Friend, J S Legge, J G Douglas
}

\begin{abstract}
Background-Studies of patient attitudes to asthma and its control have focused on crisis action, and little attention has been paid to attitudes to regular preventive medication. It is not clear whether attitudes to regular medication are related to the degree of distress or interference with life perceived by patients as being caused by their asthma. For this reason this study examined how far dislike of medication related to dislike of other aspects of interference of asthma with daily life.

Methods-Three hundred and ninety one patients were surveyed with a questionnaire which assessed their dislike of the interference of asthma with their physical, social, and emotional functioning, together with dislike of regular asthma medication. A response was received from 320 patients (82\%).
\end{abstract}

Results-Four attitude clusters were identified. Recorded in descending factor order, these were (1) dislike of asthma medication, (2) dislike of disability, (3) dislike of public life interference, and (4) dislike of social and emotional interference. The attitude clusters were not related: in particular, dislike of asthma medication could not be predicted from other dislikes, or from asthma best function ratio (ratio of best recorded peak expiratory flow rate in the previous year to predicted value), age, or sex. The most significant predictors of the patients' dislike of taking their own inhaled steroid were (1) dislike of using bronchodilator, (2) dislike of steroids generally, and (3) dislike of taking medicine every day.

Conclusions-Patient attitudes to regular asthma medication are not related to general anxieties and dislikes about asthma, nor to the potential for asthma control as judged by the best function ratio. Patients were not always consistent in their attitude to inhaled steroids in general, nor to their own named inhaled steroid in particular. A general cluster of antimedication attitudes existed, independent of whether the medication was for prophylaxis or relief. Attitudes to asthma medication may be helpful in predicting patient behaviour.

(Thorax 1993;48:827-830)
Modern asthma management uses a complex set of strategies. A patient with moderate asthma will have a bronchodilator for symptomatic relief and probably an inhaled steroid for preventive (prophylactic) management. He or she may also have a spacer attachment for an inhaler, a peak flow meter to monitor lung function, and doctor's guidelines for action when breathless or in response to falls in peak flow. A patient who has severe episodes may have a supply of oral steroids at home to be taken according to these guidelines. With this equipment a patient must organise a regular daily pattern of medication and make judgements as to when to take additional treatment.

Studies of patient attitudes have focused on crisis or relief action ${ }^{12}$ and little is known of patient attitudes to prophylactic medication. Sibbald asked patients whether and when they would use medication in attacks, and found patients with higher morbidity were more reluctant to use medication to control attacks. ${ }^{3}$ We have therefore investigated patient attitudes to regular asthma management and self medication and related this to other asthma attitudes, asthma control, and demographic characteristics.

\section{Methods}

\section{PATIENTS}

Three hundred and ninety one patients with asthma (with $20 \%$ reversibility to oral steroid or nebulised bronchodilator) attending outpatient chest clinics in the Grampian health area were sent a questionnaire with an asthma education booklet (see end of paper). All patients were taking part in the education programme of the Grampian Asthma Study in Integrated Care. ${ }^{4}$ Questionnaires were returned by $333(85 \%) ; 13$ of these did not contain enough information, leaving a final sample of $320(82 \%)$ of the original group for analysis. Ages of patients replying ranged from 17 to 83 years with a mean of 53 years. There were 140 men and 180 women in the sample analysed.

\section{STUDY DESIGN}

The questionnaire covered four types of "asthma dislikes": (1) dislike of physical dysfunction and morbidity, (2) dislike of social and emotional interference, (3) dislike of interference with public life, and (4) dislike of medication. In order to assess the emotional 
impact of the effect of asthma the deliberately emotive term "dislike" was used in the attitude items. The questionnaire took a number of standard quality of life questions ${ }^{5}$ (breathlessness on exertion, poor sleep, asthma hindering ability to do things) and asked whether these effects were disliked by patients, rather than only whether patients acknowledged that the effects existed. Dislike of behaviour associated with self management was assessed by five questions which distinguished between different types of medication: it seemed important to assess whether patient attitudes to medication vary with the type of medication. Finally, perceived social emotional and public life interference from asthma were assessed by questions based on those of Sibbald $^{3}$ who has shown that these types of attitudes have little relationship to intended use of bronchodilators: it seemed worthwhile to explore further the relation (or lack of relation) between general distress in asthma and attitudes to using prophylactic medication. Dislike of inhaled steroid was assessed independently from dislike of own named inhaled steroid in the belief that we cannot assume consistency between generalised dislike of medication and attitude to one's own medication.

A preliminary pilot survey of 35 patients had asked for open ended responses to the question: "What do you dislike about having asthma?" These responses were used to supplement items constructed as described above. The two items mainly based on patient open ended responses referred to anxiety about asthma getting worse with age and dislike of asthma interfering with family life.

We created a best function ratio (BFR) as the ratio of a patient's best recorded peak expiratory flow rate (PEF) to the predicted PEF over the year before completing the questionnaire. By taking the best PEF achieved over the preceding year we hoped to measure functioning at optimum control for patients-that is, the best achievable level.

\section{STATISTICAL ANALYSIS}

Factor analysis (principal components with Varimax rotation $)^{6}$ was used to identify clusters of dislikes. A factor was considered important if its eigen value (a statistical measure of its power to explain variation between patients) exceeded 1.0 as recommended by Joliffe and Morgan. ${ }^{7}$ Stepwise logistic regression analysis ${ }^{8} 9$ was used to test whether differences in age, sex, BFR, or other asthma dislikes predicted dislike of own named inhaled steroid. Because we believed that attitudes to inhaled steroids in general might not be consistent with attitudes to own named steroid, we evaluated attitudes to both. Each patient questionnaire used the specific name of the medication taken from the patient's records, inserted by computerised merging.

\section{Results}

Clusters of patient attitudes to asthma are shown in table 1 . The first column shows the number responding positively to each question about dislikes; the remaining columns show the largest factor loading for each item. Four clusters of attitudes can be clearly identified: (1) dislike of medication, both relief and preventive; (2) dislike of disability (dislike of physical limitations and breathlessness, dislike of being unable to do things because of asthma); (3) dislike of interference with public life (use of an inhaler in public and being wheezy in public); (4) dislike of social and emotional interference (worry about asthma and its effects on personal and family relationships).

Each cluster of items was assessed for scale reliability using Cronbach's alpha coefficient. ${ }^{6}$ The dislike of medication cluster had good interitem reliability with a coefficient of 0.77 : the other three clusters had relatively poor reliability with coefficients between 0.40 and 0.50 .

Having identified clusters of attitudes using factor analysis we could give respondents a score on each factor calculated from factor

Table 1 Patient attitudes to asthma: factor clusters

\begin{tabular}{|c|c|c|c|c|c|}
\hline Questions & $\begin{array}{l}\text { Percentage } \\
\text { (of 320) who } \\
\text { replied "yes" }\end{array}$ & $\begin{array}{l}\text { Factor } 1^{\star} \\
\text { (dislike of } \\
\text { medication) }\end{array}$ & $\begin{array}{l}\text { Factor } 2^{\star} \\
\text { (dislike of } \\
\text { disability) }\end{array}$ & $\begin{array}{l}\text { Factor } 3^{\star} \\
\text { (dislike of } \\
\text { interference with } \\
\text { public life) }\end{array}$ & $\begin{array}{l}\text { Factor } 4^{*} \\
\text { (dislike of social } \\
\text { and emotional } \\
\text { interference) }\end{array}$ \\
\hline $\begin{array}{l}\text { Dislike using daily medication } \\
\text { Dislike inhaled steroids } \\
\text { Dislike using own relief medication } \\
\text { Dislike using own inhaled steroid } \\
\text { Dislike using oral steroids }\end{array}$ & $\begin{array}{l}31 \\
28 \\
16 \\
21 \\
38\end{array}$ & $\begin{array}{l}0.70 \\
0.77 \\
0.75 \\
0.84 \\
0.48\end{array}$ & & & \\
\hline $\begin{array}{l}\text { Dislike using inhalers in public } \\
\text { Dislike wheezing in public }\end{array}$ & $\begin{array}{l}54 \\
79\end{array}$ & & & $\begin{array}{l}0 \cdot 72 \\
0 \cdot 78\end{array}$ & \\
\hline $\begin{array}{l}\text { Worry asthma will worsen with age } \\
\text { Worry about attacks } \\
\text { Asthma makes me grumpy with family }\end{array}$ & $\begin{array}{l}65 \\
57 \\
50\end{array}$ & & & & $\begin{array}{l}0.60 \\
0.67 \\
0.66\end{array}$ \\
\hline $\begin{array}{l}\text { Dislike asthma interfering with sleep } \\
\text { Dislike breathlessness } \\
\text { Dislike being unable to do things }\end{array}$ & $\begin{array}{l}53 \\
87 \\
73\end{array}$ & & $\begin{array}{l}0.43 \\
0.77 \\
0.77\end{array}$ & & \\
\hline $\begin{array}{l}\text { Eigen value (power to explain variation } \\
\text { between patients) }\end{array}$ & & $2 \cdot 9$ & 1.9 & $1 \cdot 2$ & $1 \cdot 2$ \\
\hline $\begin{array}{l}\text { Variance (\%) } \\
\text { Cronbach's alpha (interitem reliability } \\
\text { coefficient) }\end{array}$ & & $\begin{array}{c}22 \cdot 1 \\
0 \cdot 77\end{array}$ & $\begin{array}{c}14 \cdot 8 \\
0 \cdot 48\end{array}$ & $\begin{array}{l}9 \cdot 3 \\
0 \cdot 50\end{array}$ & $\begin{array}{l}9 \cdot 1 \\
0 \cdot 40\end{array}$ \\
\hline
\end{tabular}

^Only factor loadings above 0.4 are shown. 
Table 2 Association between attitude items and dislike of own inhaled steroid

\begin{tabular}{|c|c|c|c|c|c|}
\hline & \multicolumn{2}{|c|}{ Number who replied } & \multirow{2}{*}{$\begin{array}{l}\text { Percentage of those replying } \\
\text { "yes" who disliked own } \\
\text { inhaled steroid }\end{array}$} & \multirow{2}{*}{$\begin{array}{l}\text { Percentage of those } \\
\text { replying "no" who disliked } \\
\text { own inhaled steroid }\end{array}$} & \multirow{2}{*}{$\begin{array}{l}\text { Relative likelihood of } \\
\text { disliking own inhaled steroid } \\
\text { ( } 95 \% \text { confidence interval) }\end{array}$} \\
\hline & Yes & No & & & \\
\hline $\begin{array}{l}\text { Dislike using own bronchodilator } \\
\text { Dislike inhaled steroids generally } \\
\text { Dislike taking daily medication }\end{array}$ & $\begin{array}{r}52 \\
89 \\
100\end{array}$ & $\begin{array}{l}268 \\
231 \\
220\end{array}$ & $\begin{array}{l}75 \\
58 \\
49\end{array}$ & $\begin{array}{r}10 \\
6 \\
8\end{array}$ & $\begin{array}{c}13 \cdot 2(10 \cdot 1 \text { to } 16 \cdot 3) \\
9 \cdot 3(6 \cdot 3 \text { to } 12 \cdot 3) \\
3 \cdot 7(0 \cdot 7 \text { to } 6 \cdot 7)\end{array}$ \\
\hline
\end{tabular}

loadings on the items. The resulting medication, disability, public life, and social-emotional dislike scores were tested for differences related to sex, age, or BFR.

For the 320 patients analysed BFRs ranged from 0.3 to 1.3 with a mean (SD) of 0.79 $(0 \cdot 2)$, median 0.78 . Patients below the median for BFR were significantly more likely to say that they would avoid walking briskly $\left(\chi^{2}=23.3, \mathrm{df}=1, \mathrm{p}<0.001\right)$ and that their sleep was often disturbed by asthma $\left(\chi^{2}=\right.$ $7 \cdot 00, \mathrm{df}=1, \mathrm{p}<0.005)$. The $\mathrm{BFR}$ was significantly negatively correlated with the number of bronchodilators $(r=-0.30$, $\mathrm{p}<0.001$ ), and with oral steroid courses $(r=-0.21, \mathrm{p}<0.001)$ prescribed over one year.

Significant correlations were found between age, BFR, and the dislike of disability scores. Younger patients, and those with higher BFR values - that is, higher maximum functioning - had more dislike of disability caused by asthma $(r=-0.28$, age: $\mathrm{p}<0.05$; $r=0 \cdot 24$, BFR: $\mathrm{p}<0.01)$. Men scored higher on the dislike of interference with public life factor $(t=1.92, \mathrm{df}=317, \mathrm{p}<0.06)$. The dislike of medication did not correlate significantly with age, sex, other patient attitudes, or with BFR.

The dislike of medication cluster is quite distinct from other factors. In other words, patient attitudes to medication are not related to dislike or distress at other aspects of asthma interference with their life, and dislike of disability caused by asthma does not predict any greater acceptance of regular medication.

Although attitudes to inhaled steroids generally and to own named inhaled steroid were significantly related, patients were not always consistent in their response. Of the 89 patients who said they disliked inhaled steroids in general, $37(42 \%)$ said they did not dislike their own named inhaled steroid. To see which items best predicted a patient's dislike of using own named inhaled steroid we used the technique of stepwise logistic regression analysis. ${ }^{89}$ The regression equation was derived by testing each attitude question from the dislikes scale and demographic variables for effectiveness in predicting dislike of own inhaled steroid. At each step the item which most improved this prediction was added. The process stopped when no additional item could improve the significance of the model by an amount significant at the 5\% level. Table 2 shows the only three questions which fulfilled these criteria for inclusion: patients who disliked using their own bronchodilators were 13 times more likely to dislike using their own inhaled steroid, patients who disliked inhaled steroids were generally nine times more likely to dislike their own steroid, and patients who disliked daily medication had a four fold dislike of their own steroid. From responses to these three questions a correct prediction of attitudes to own inhaled steroid could be made for $89 \%$ of patients.

\section{Discussion}

This study shows a strong and consistent cluster of negative patient attitudes to asthma medication. These antimedication attitudes were not related to a constructed BFR, where this ratio was strongly associated with the number of bronchodilators and oral steroid courses prescribed, and therefore appears to be a valid measurement of maximum control achievable. Quirk and Jones ${ }^{10}$ have shown a separation between distress at the effects of asthma and perceived degree of interference of those effects with daily life. In their study, distress at the effects of asthma was not linked to age, sex, variability of asthma, or time since diagnosis. Similarly, in our study, attitudes to medication were also not predictable from perception of interference and dislike of the effects of asthma, and did not relate to age, sex, or BFR.

All the patients in this study were under specialist care and were taking part in an educational programme based on mailed booklets giving self management advice. Attitudes to medication and knowledge about it may differ among this group from a general practice population whilst, conversely, psychological distress may be greater. It would be of interest to see if the same strong clustering of antimedication attitudes is present among a milder population of asthmatic subjects, and how far the dislike of medication use correlates with reported compliance.

It has been argued that patients have different attitudes to relief and prophylactic medications, and that they are more willing to use relief medication (bronchodilators) than inhaled corticosteroids. The results from the present study show little distinction between patient attitudes to relief and prophylactic medicines. The strongest predictors of dislike to preventive medication were dislike of using a relief inhaler, dislike of taking medicine regularly, and dislike of inhaled steroids generally. Harding and Modell ${ }^{11}$ found a "deep seated distrust of long term medication based on fears of possible side effects and dependence." More than one third of patients disliked having to use any sort of asthma medication. Kaptein et $a l^{12}{ }^{13}$ found that $24 \%$ of a Dutch general practice population of 
asthmatic patients would delay taking appropriate medication when breathless. Sibbald ${ }^{3}$ reported reluctance to use medication in attacks, particularly among older patients.

If patients and doctors are to gain maximum benefit from the British Thoracic Study ${ }^{14}{ }^{15}$ guidelines for the stepwise management of asthma, patients need to be confident and competent in their use of preventive medication. Patients who dislike taking medication will be more at risk of severe episodes and may be less likely to actively provide their doctors with information important for their management. Similarly, doctors need to be aware of a patient's dislike of taking asthma medication. For many patients the addition of any regular daily medication to an "as required" medication will be a difficult step and the regular use of any inhaler, relief, or prevention may be disliked. A better understanding of attitudes to asthma medication should be helpful in encouraging good patient adherence to treatment.

\section{Asthma dislikes questionnaire}

What do you dislike about having asthma?

Taking an inhaled steroid

Using inhalers in public

Being wheezy in public

Feeling anxious about controlling a bad attack

Not being able to do things I would like to do

Getting breathless when I hurry or exert myself

Getting grumpy or bad tempered with family or friends because of my asthma

Worrying about whether my asthma will get worse as I get older

Using 1

Using ${ }^{2}$

Taking oral steroid tablets

Taking medicine every day

Not sleeping well

1 Computerised insertion of own named inhaled steroid 2 Computerised insertion of own named bronchodilator
We thank Dr David Elston for helpful comments in the development of this paper. The GRASSIC educational programme, from which these results have been drawn, was funded by Allen and Hanburys, whom we thank for their support. The Health Service Research Unit is funded by the Chief Scientist's Office of the Scottish Office, Home and Health Department. However, the opinions expressed in this paper are those of the authors, not the SHHD.

1 Tobin DL, Wigal JK, Winder JA, Holroyd KA, Creer TL. The "asthma self efficacy" scale. Ann Allergv 1987;59:273-7.

2 Richards JM, Dolce JJ, Windsor RA, Bailey WC, Brooks CM, Soong S. Patient characteristics relevant to effective self management: scales for assessing attitudes of adults toward asthma. f Asthma 1989;26:2, 99-108.

3 Sibbald B. Patient self care in acute asthma. Thorax 1989;44:97-101

4 Osman LM, Abdalla MI, Beattie JAG, Ross SJ, Russell IT, Friend JAR, et al. Reducing hospital admissions through a computer supported asthma education programme. BMF 1993 (paper submitted for publication)

5 Guyatt GH, Townsend M, Berman LB, Pugsley $O$. Quality of life in patients with chronic airflow limitation. Br f Dis Chest 1987;81:45-54.

6 SPSS Inc. Statistical Package for the Social Sciences. Release 4. Chicago:SPSS, 1990

7 Joliffe IT, Morgan BJT. Principal components analysis and exploratory factor analysis. Stat Methods Med Res 1992;1:69-95.

8 Armitage P, Berry G. Statistical methods in medical research. 2nd edn. Chichester: Wiley, 1987.

9 Russell IT, Gregson B. Trainee's assessments of their trainers: statistical analysis. In: Ronalds C, Douglas A Gray DJP, Selley P, eds. Occasional Paper 18. London: Royal College of General Practitioners, 1981.

10 Quirk FH, Jones PW. Patients' perception of distress due to symptoms and effects of asthma on daily living and investigation of possible influential factors. Clin $S c$ 1990;79:17-21.

11 Harding JM, Modell $\mathrm{M}$. How patients manage asthma. $f$ $R$ Coll Gen Pract 1985;35:226-8.

12 Kaptein AA, Dekker FW. Health psychology and asthma: current status and future directions. In: Maes $S$, Spielberger CD, Defares PB, Sarason IG, eds. Topics in Health Psychology. Chichester: Wiley, 1988:157-70.

13 Kaptein AA, Dekker FW, Gill K, Van der Waart MAC. Under treatment of asthma in Dutch general family practice. Fam Pract 1987;43:219-25.

14 British Thoracic Society and others. Guidelines for the management of asthma: a summary. BMY 1993 306:776-82.

15 British Thoracic Society and others. Guidelines on the management of asthma. Thorax 1993;48(Suppl):S1-24. 